\title{
COMPORTAMENTO E BEM-ESTAR DOS PINGUINS DE MAGALHÃES (SPHENISCUS MAGELLANICUS) DO AQUÁRIO NATAL
}

\section{BEHAVIOR AND WELL-BEING OF THE MAGALHÃES PENGUINS (SPHENISCUS MAGELLANICUS) OF AQUÁRIO NATAL}

\author{
Apresentação: Pôster \\ Matheus Melo Dantas ${ }^{1}$; Maria Lucivânia Diniz da Silva²; Brena Karisa Campos de \\ Melo $^{3}$; Laércio Nogueira Medeiros ${ }^{4}$; Viviane da Silva Medeiros ${ }^{5}$ \\ DOI: https://doi.org/10.31692/2526-7701.IIICOINTERPDVAGRO.2018.00385
}

\section{Introdução}

Os pinguins-de-magalhães (Spheniscus magellanicus) são a espécie de pinguim de maior ocorrência na costa brasileira, possui pequeno/médio porte, tendo em vista sua altura, que varia entre 60 e 70 centímetros, e seu peso, entre 3,5 e 4 quilos, sendo essas as características mais variáveis e mais importantes para distinção das espécies de pinguins, pois as demais existentes são uniformes em sua morfologia e coloração (SOUZA et al. 2007). Gregários, esses animais se reúnem em grandes colônias na costa do Chile, Argentina e Ilhas Malvinas para se reproduzir.

Segundo a International Union for Conservation of Nature (2016), os pinguins-demagalhães são classificados como uma espécie quase ameaçada de extinção, com uma tendência atual de diminuição para as populações. O derramamento de petróleo, a relação com a pesca e as mudanças no clima são os principais fatores que ameaçam a vida desses animais (IUNC, 2016), o que faz com que muitas vezes eles acabem chegando ao litoral brasileiro debilitados, incapacitados de voltar para a natureza e posteriormente encaminhados a centros de reabilitação e à vida em confinamento.

A qualidade de vida em aquários e zoológicos é significativamente inferior à da vida na natureza, pois o cativeiro é um fator limitador, levando muitos animais a terem seu comportamento alterado em função do confinamento em locais que não lhes proporcionam as

\footnotetext{
${ }^{1}$ Medicina Veterinária, UFCG, melodantasm@gmail.com

${ }^{2}$ Zootecnia, UFRN, maria.lucivania1@live.com

${ }^{3}$ Zootecnia,UFRN, Brenacampos16@hotmail.com

${ }^{4}$ Mestrando PRODEMA, UFRN, laerciomedeiros2015@gmail.com

${ }^{5}$ Doutora em Psicobiologia, UFRN, vivianemedeiros.eaj@gmail.com
} 
mesmas condições do ambiente natural, o que interfere no bem-estar dos mesmos (SOUZA \& ANDRADE, 2009). Assim, é vista a necessidade de avaliar o conforto e as condições oferecidas aos pinguins-de-magalhães do Aquário Natal.

\section{Fundamentação Teórica}

Os Pinguins-de-Magalhães de vida livre e cativos apresentam um ciclo de vida definido. Em seu habitat, durante os meses de maio a agosto essa ave permanece no mar, até mesmo dormindo à deriva, nos meses de setembro a março os pinguins cuidam dos ovos ou filhotes, porém ainda necessitam voltar ao mar, passando um tempo considerável, em busca de alimentos; nos meses de março e abril as aves permanecem de 2 a 3 semanas em terra, devido a troca de plumagem, que diminui a permeabilidade das penas. (Williams e Boersma, 1995; Cranfield, 2003; Silva-Filho e Ruoppolo, 2007) apud (Argentin, 2015). Em contrapartida, os Pinguins-de-Magalhães em cativeiro, são mais sedentários, possuem menos estímulos, como a busca de alimento dentro d'água, isso ocasiona menor quantidade de tempo dentro dos tanques. A falta de atividade causa problemas de saúde, como a pododermatite, que é muito frequente em pinguins de cativeiro. Com intuito de diminuir a ocorrência faz-se necessário que os recintos dessas aves apresentem enriquecimento ambiental com mudanças físicas e sensoriais (Argentin, 2015).

\section{Metodologia}

A pesquisa foi realizada no pinguinário do Aquário Natal. O local possui sete animais, sendo cinco pinguins-de-magalhães (Spheniscus magellanicus), uma gaivota (Larus delawarensis) e uma fragata (Fregata aquila). Para avaliar o conforto, os animais foram observados no turno vespertino durante uma hora, com um intervalo de cinco minutos entre cada observação, por cinco dias consecutivos. Em função da avaliação dos animais sem marcação, foram anotadas toda atividade possível em cada janela de tempo. Os comportamentos avaliados foram: repouso em pé (RP), repouso deitado (RD), arrumando penas $(\mathrm{AP})$, nadando $(\mathrm{N})$ e olhando $(\mathrm{O})$. Para qualificação do recinto foram tomadas as medidas de área e foram avaliados os elementos que compõem o ambiente quanto às necessidades da espécie. Os parâmetros de qualidade da água, tais como: pH, nitrito, salinidade e temperatura, foram avaliados através de kits de reagentes colorimétricos, refratômetro e termômetro digital, respectivamente. Os resultados obtidos foram colocados em gráficos e suas médias foram calculadas em função dos dias. 


\section{Resultados e Discussões}

\subsection{ANÁLISE COMPORTAMENTAL DOS PINGUINS-DE-MAGALHÃES}

(SPHENISCUS MAGELLANICUS)

Os pinguins são aves que passam grande parte do dia no mar, sendo os melhores mergulhadores de todas as aves (SOUZA, 2007). Entretanto, a pesquisa realizada apresentou que em grande parte do tempo os animais permanecem em repouso, majoritariamente em pé.

No intervalo diário observado, os animais apresentaram o comportamento de repouso em pé (RP) de $12-55 \%$ do tempo, representando $38 \%$ da média dos 5 dias observados, sendo o comportamento mais apresentado entre os animais.

Assim como no estudo realizado por SOUZA (2012), em todos os intervalos do dia houve prevalência nos comportamentos "repouso" (12-55\%), especificamente em pé, "Olhar" (13-34\%) e "arrumar penas" (8-33\%). Sem levar em conta os comportamentos de "Repouso deitado" (5\%) e "Locomoção" (1\%), o comportamento de menor frequência média foi o de "nadar", que variou de $0-36 \%$, porém correspondendo a apenas $14 \%$ da média geral, o que é bem abaixo do que se espera para esses animais.

Figura 1 - Frequência média dos comportamentos diários no intervalo de 13:30 - 14:30 (horas) Comportamentos descritos: RP: repouso em pé, RD: repouso deitado, N: nadar, O: olhar, AP: arrumar penas e L:

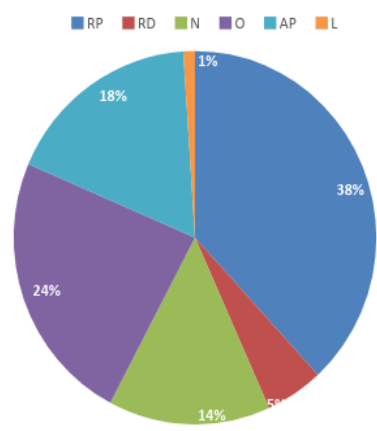

locomoção. Comportamento e bem-estar dos P. de magalhães do A. Natal. Fonte: Própria

Figura 2 - Frequência dos comportamentos diários observados no intervalo de 13:30 - 14:30 (horas). Comportamentos descritos: RP: repouso em pé, RD: repouso deitado, N: nadar, O: olhar, AP: arrumar penas e L: locomoção. Comportamento e bem-estar dos P. de magalhães do A.Natal. Fonte: Própria

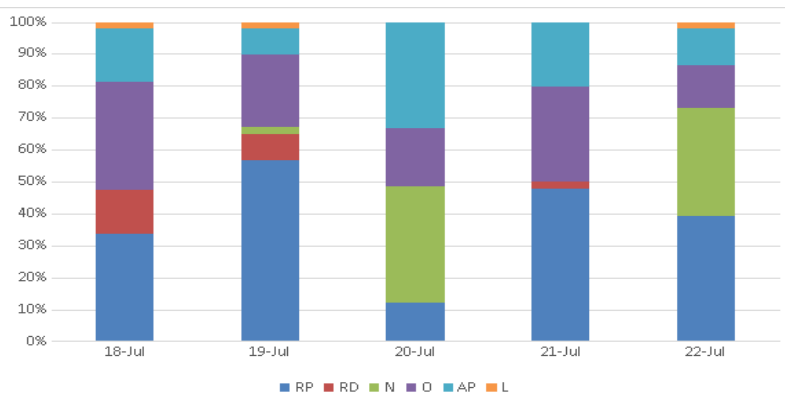


A falta de atividade no primeiro dia de observação pode ser entendida pelo fato de que estava havendo a limpeza do recinto e os animais estavam confinados em uma pequena área (apróx. 1/4) do recinto. A partir desse dia, pode-se observar que há banhos, embora as atividades em área seca ainda sejam as preferenciais dos animais. Tal preferência pode ser decorrente da falta de estímulo, seja social ou reprodutivo.

Diferente dos pinguins apresentados por SOUZA (2012), nenhum pinguim no Aquário Natal apresentou comportamento de "colher material" para formação de ninhos, mesmo possuindo um "buraco" com pedregulhos no recinto. Embora haja disponibilidade, um dos casais estava chocando irregularmente um ovo em ninhos feitos sem o uso desse material, talvez pelo excessivo tamanho dos seixos. Em nenhum momento das observações os turistas ou as outras aves presentes no recinto causaram interferência com os pinguins.

\subsection{QUALIFICAÇÃO DO RECINTO}

O pinguinário possui uma área de $115,3 \mathrm{~m}^{2}$, com área seca e piscina. A área seca é forrada com areia de praia, possui rochas nas extremidades opostas a piscina e "casinhas" plásticas para acomodar os animais, além de uma pequena área com seixos para estimular a reprodução.

Segundo SILVA (2007), a piscina do recinto deve possuir rampa levemente inclinada e de fácil acesso aos animais, sua profundidade também não deve ser inferior a 1,3m. Nesses quesitos, o pinguinário se encontra nos padrões, porém no que se refere à qualidade da água, o ambiente deixa a desejar.

É recomendado o uso de bombas de alta pressão com filtros de areia e o uso de skimmers, para manter a clareza e retirar o excesso de óleo proveniente da defecação e alimentação. A piscina do Aquário não possui filtragem ou quaisquer movimentações na água, tornando-a poluída em decorrência da grande quantidade de fezes.

\subsection{QUALIDADE DE ÁGUA}

A qualidade da água da piscina dos pinguins apresentou bons parâmetros quanto ao $\mathrm{pH}(7,3-7,8)$, salinidade $(36-38 \mathrm{ppm})$ e temperatura $\left(16,5-22,5^{\circ} \mathrm{C}\right)$. No entanto, o nitrito se mostrou muito elevado, o que pode vir a prejudicar a qualidade de vida dos animais.

Segundo a EMBRAPA (2005), os parâmetros de qualidade da água de bebida para suínos e aves, em relação ao nitrito, não deve ser superior a 1,0mg/l. O nitrito na piscina dos pinguins apresentou valores que variaram de 1,0-2,80mg/l, sendo que as concentrações mais 
baixas foram coletadas de 4 a 7 dias após troca total de água. Geralmente tenta-se fazer essa troca a cada 15 dias, mas a frequência com que é feita a limpeza do recinto é irregular na maioria das vezes, o que ajuda no acúmulo de matéria orgânica e sucessivamente no alto teor de nitrito.

Figura 3 - Valores da concentração de nitrito da piscina dos pinguins do Aquário Natal. Fonte: Própria

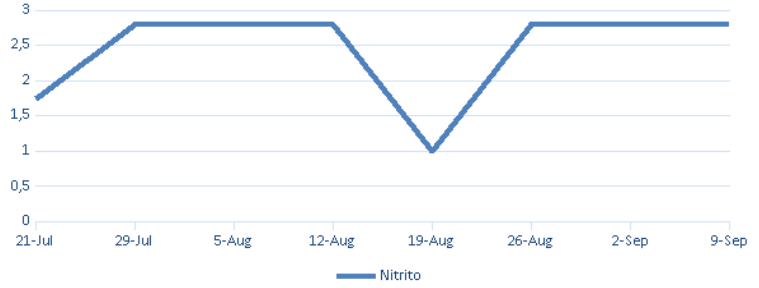

\section{Conclusões}

Ao final deste trabalho, conclui-se que os pinguins alojados no Aquário Natal estão num recinto em tamanho adequado, entretanto ficam pouco tempo em atividade de nado, provavelmente por conta da qualidade da água estar acima dos padrões de nitrito admissíveis para aves. Não se encontrou na literatura dados sobre a qualidade de água ideal para pinguins em cativeiro, sugere-se que novos estudos sejam realizados para este fim.

\section{Referências}

ALMEIDA, António. Como se posicionam os professores perante a existência e utilização de jardins zoológicos e parques afins? Resultados de uma investigação. Educação e Pesquisa, v. 34, n. 2, 2008.

BARROS, Y. M. Zoos e aquários têm papel importante na conservação. Portal da Associação O Eco. Disponível em: http://www. oeco. org. br/convidados/27224zooseaquariostempapelimportantena conservacao/Acesso em, v. 29, 2014.

BirdLife International. 2016. Spheniscus magellanicus. (versão alterada publicada em) Lista Vermelha da UICN de Espécies Ameaçadas 2016: e. T22697822A119167908.

DE REGISTROS ORNITOLÓGICOS, CBRO-Comitê Brasileiro. Listas das aves do Brasil. $11^{\mathrm{a}}$ Edição, 2014.

LARISSA DAMINELLI. Enriquecimento ambiental para o bem-estar na recuperação do Pinguim-de-Magalhães (Spheniscus magellanicus). Florianópolis, 2017. 24 p. Projeto de Trabalho de Conclusão de Curso. Departamento de Ecologia e Zoologia, UFSC, 2017.

PALHARES, Júlio César P. Qualidade da água para suínos e aves. Empresa Brasileira de Pesquisa Agropecuária, 2005. 
PEREIRA, Lilian Barbosa; ALMEIDA, A. R. V.; SOARES, Anísio Francisco.

Enriquecimento ambiental para animais que vivem em cativeiro. Anais da IX Jornada de Ensino, Pesquisa e Extensão. Recife: UFRPE, 2009.

SILVA, J. C. R.; CATÃOdIAS, Z. S. Tratado de animais selvagens. São Paulo: Roca $\mathbf{1}^{\text {a }}$ edição, 2007.

SILVEIRA, P. H. Manejo e controle de pododermatite em Pinguim-de-Magalhães (Spheniscus magellanicus Foster 1781) no aquário de Ubatuba situado em Ubatuba - SP. Curitiba, 2017. 62 p. Dissertação. Faculdade de Ciências Biológicas e da Saúde, UTP, 2017. 